\title{
A Study on the Mechanism of New Value Creation: From the View of Entrepreneurial Mental Model Presencing
}

\author{
Li Weidong, a Li Li $^{2, b}$ \\ ${ }^{1,2}$ Xiamen University School of management,Xiamen,Fujian,361005,China \\ A,bdanhonghuang@126.com
}

Keywords: Entrepreneur, New Value Creation, Mental Model

\begin{abstract}
The existing research based on the paradigm of Environmental Adaptation Theory leads to an explanation of entrepreneurial mental process from a extrinsic, historical and static view. They also cannot explain why entrepreneur choose to open a new company themselves instead of selling entrepreneurial opportunities to others which can also brings entrepreneurial profits. This study is based on the paradigm of Constructivism. Our model systematically explains entrepreneurial process from the view of mental model presencing by borrowing theories from Humanistic Psychology. The process is divided into 3 stages__ Opportunity Emergence, Value Realization, and Value Diffusion, while Value Realization has 3 steps_-Value Focus, Policy Establishment, and Mode Anchor. The exclusivity of entrepreneurial opportunity is from the implicitness of entrepreneurial mental model in the first stage. New value realization is highly relied on entrepreneurial mental model, which is the source of new company's mission, vision, and core competence.
\end{abstract}

\section{Introduction}

The paradigm of environmental constructivism is rooted in different understandings on the situation of human beings; according to Humanistic Psychology, human beings are unique creatures in the natural world; as human beings are endowed with rationality and imagination, they have the intention and power to change the world creatively. Based on this, environmental constructivism believes that human beings construct their own environment according to their own subjective beliefs (Shackle, 1979[i]; Weick, 1979[ii]). Entrepreneurial opportunity creation view based on the paradigm of environmental construction believes that opportunities are endogenous, and they are results of striving efforts based on the vision and imagination according to entrepreneurs' brain (Hill \& Levenhagen, 1995 ) [iii]; Sarasvathy, 2001[iv];Baker \& Nelson, 2005[v];Dimov, 2007[vi];Felin \& Zenger, 2009[vii]). These studies disclose the process of entrepreneurs' construction of external environment through their mental development from aspects of entrepreneurs' mental models (Hill \& Lavenhagen, 1995[7]), entrepreneurial intentions (Bird, 1988[viii], 1992[ix]), entrepreneurs' perception (Felin \& Zenger, 2009[11]; Wood \& Mckinley, 2010[x]) and entrepreneurs' emotions and feelings (Baron, 2006[xi]; Cardon et al., 2009[xii]). However, previous studies have either not showed the source of values or imply the exitence of value, but they have not answered the question of how the new value idea and its realization to sprout, grow up, get mature and consolidate systematically and clearly.

\section{Research Framework}

The entrepreneurial studies based on the view of opportunity discovery believes that the essence of entrepreneurship is to discover and exploit entrepreneurial opportunities; therefore, they proposed to develop this process according to the research mainline of "recognition - exploitation - utilization of entrepreneurial opportunities"(Shane \& Venkataraman, 2000[3]). This view believes that the recognition of entrepreneurial opportunities is the core stage of the creation of new value; the knowledge and information on new value are complete in this stage; information barriers are important shield for others to enter the entrepreneurial field and the other shield is that entrepreneurs 
combine information into unique cognitive characteristics of entrepreneurial plan, and these two points determine the discovery of entrepreneurial opportunities before entrepreneurial actions (Shane \& Venkataraman, 2000[3]). However, under these circumstances, individuals with entrepreneurial opportunity information don't have to start a business with risks themselves and they can sell entrepreneurial opportunities to others to bring entrepreneurial profits. However, if they sell the opportunities, entrepreneurship completely becomes activities of searching for and dealing with information, and those who do the entrepreneurial practice are just "makers" instead of "creators" of new value, which undoubtedly doesn't correspond to the entrepreneurship phenomena in real life.

\section{Emergence of Entrepreneurial opportunities}

Source of entrepreneurial opportunities: Classic entrepreneurial theory believes that entrepreneurial opportunities come from unclear market demand and untapped resource and capacity (Kirzner, 1997[2]), the essence of which is the possibility of satisfying market demand through transmitting higher value with innovative resource combination. This paper believes that entrepreneurial opportunities are results of entrepreneurs' voluntary creation to break the existing balanced state of economic system. Entrepreneurial opportunities are a kind of unique cognition different from the others constructed by entrepreneurs, which make entrepreneurs start to regard their previous experience and outer world with new view; economic system becomes unbalanced under new view and entrepreneurs see their and other people's unsatisfied demand.

Source of creative motivation: Another important needed to solve in the disclosure of entrepreneurs' psychological process of creating entrepreneurial opportunities actively is the motivation of entrepreneurs want to change their present balanced state? The mainstream entrepreneurial theories suppose that the motivation of forming entrepreneurial intention for entrepreneurs is to gain entrepreneurial profits (Kirzner, 1997[2]; Shane \& Venkataraman, 2000[3]) . However, in the initial stage of entrepreneurship, as new products or services have not become mature, new enterprises cannot get abundant and steady income in this stage; moreover, the economic returns in the future are uncertain, and thus, under this circumstance, it's not enough to just explain entrepreneurial opportunities as the desire for entrepreneurial profits.

Basically speaking, the creativity of human beings comes from their independent consciousness beyond environment (Fromm, 1959[4]). Consequently, as Jobs says, "to live, is to change the world", the basic motivation for entrepreneurs to break present balanced state of economic system lies in the inner creative opportunities of human beings.

Mechanism of opportunity emergence: Although creative motivations, as an important component of human nature, exist in every person, creativity cannot smoothly exerted on every person; the entrepreneurs' mental state has specific characteristics before opportunity emergence. This means that people are not unchanging entities but a collection of choice specimens with constantly changing potentials (Rogers, 1980[18]) . Kirzner (1979) [xiii]puts forward the concept of entrepreneurs' "alertness"; "alertness" substantially is a kind of entrepreneurs' desire state under the influence of creative motivations; entrepreneurs start to offer sufficient opportunities of emergence of inner emotions, and they get sensitive, curious, and long for changes. This state provides motive power for levering entrepreneurs' present mental model and it is also the origin of mental model development related to the creation of new value.

Process of opportunity emergence: Presently, active emotion emergence will stimulate individuals' reflexive thoughts and make them spontaneously create, maintain and change the external social and economic state; therefore, when the prerequisite mental state is possessed, novel and original cognition will spring up autonomously. The cognition surpasses all the previous experience of individuals and is brand new. In this process, new cognition becomes independent object away from the subject of cognition-- entrepreneurs' consciousness for the first time and lays the foundation for the production of instrumental knowledge.

The entrepreneurial opportunities which exist as self-transcendence knowledge has the following two features: (1) Exclusivity. As self-transcendence knowledge belongs to implicit cognition without 
embodiment and cannot be expressed through previous lingual system, more difficult to transmit and disperse than implicit knowledge (Scharmer, 2001)[23], it's difficult for entrepreneurs to truly share the entrepreneurial opportunities with the others; thus, they get the entrepreneurial opportunities exclusively. (2) Ambiguity. Entrepreneurial opportunity is a brand new angle to look at the outer world that is constructed by entrepreneurs; as a kind of cognition separated from emotional experience, it is combined by emotional feelings and unconscious acquirement (Hill \& Lavenhagen, 1995[7]); just as an embryo without undifferentiation, it contains ample possibilities, but it's impossible to foresee it's appearance after growing up. Based on the explanation on the mechanism of opportunity emergence, this paper puts forward Proposition 1: the premise for the emergence of entrepreneurial opportunities is that entrepreneurs hold an open attitude towards their own emotional experience, which is embodied in such psychological state as being sensitive, curious and longing for changes. Entrepreneurial opportunities are a kind of entrepreneurs' unique cognition of initiative creativity, which is difficult to express or transmit and is exclusive and ambiguous. It provides entrepreneurs with brand new view to look at the world and contains possibilities of producing new value.

\section{Value Realization}

The emergence of entrepreneurial opportunities lays foundation and basis for the value-creation activities, but at this time, the content of new value is not clear yet. Entrepreneurs need to pay great mental efforts to realize new value. Generally speaking, entrepreneurs need to define the specific content of new value, to make the management guideline that suits the intrinsic requirements of new value and to form stable behavioral pattern in the management of enterprises. Therefore, this paper divides the process of value realization into three stages of value focus, policy establishment, mode anchor and elaborates the mental process of entrepreneurs included in the three stages.

Value focus: Entrepreneurial opportunities endow entrepreneurs with brand new view to look at the world; the economic system that seems perfect becomes full of loopholes in this perspective; new customer value starts to appear. The essence of value is a kind of emotional experience; any kind of value needs people's feelings, experience or perception (Scheler, 1991)[xiv]. The self-regulation theory in the field of sociology (Carver \& Scheier, 1998) provides references for us to understand the process of entrepreneurs' value focus. Self-regulation mechanism mainly influences two aspects: (1) it is a kind of human agency mechanism and prompts individuals to focus on deep experience brought by new value with efforts and consciously, which makes entrepreneurs create abundant objects of potential values and think deeply about it, and at the same time, it coordinates cognition and behaviors to focus on value realization. (2) it is a kind of human coping mechanism, which makes individuals' body and brain put into certain target and replies to the challenges met in the process of target realization. The essence of self-regulation mechanism is various choices on the concurrent state of individuals' experience and emotions, and the management and control on the evoked cognition process from experience. Therefore, it makes entrepreneurs' choice faithful to their most authentic feelings and choose those value objects which can bring long-term and deep-level sense of joy.

Policy establishment: After entrepreneurs clarify their targets or visions of entrepreneurship, they need to think about the paths and methods of realization, which is showed in the process of entrepreneurs' mental model development; it is also the belief development of ultimate goals and the corresponding instrumental cognition. Felin \& Zenger (2009) [11] points out that under the guidance of inner value pursuit, entrepreneurs will start to make imaginations on all kinds of possible action procedures, which include possible new market, new products, new management structure and so on; then, through reasoning and verifying, those action steps that are illogical or difficult to realize entrepreneurs' value pursuit will be denied and those rules of conduct that are logical and subject to value realization needs will become entrepreneurs' beliefs and be practiced by them.

Mode anchor: In the real experience, besides existed certain targets or visions and specific business policies, new entrepreneurs show stable behavioral styles or patterns, such as some enterprises like to launch new products through low-price promotion and some enterprises prefer 
propagandizing with carpet advertising campaign. The differences of these outer behavioral styles actually imply the uniqueness of entrepreneurs' inner psychological process. This kind of cognition will promote him to act according to the stated behavioral patterns and these acts will make external environment change along with the given directions, which will further enhance individuals' setting; individuals construct outer environment in the process of this kind of interaction. From this, it can be seen that individuals' behavioral patterns are subject to their basic setting for the future or the external environment; but as for entrepreneurial process, this kind of setting is the goal and vision of entrepreneurs and the business policy serving the goal and vision. Therefore, schema lies in the shallowest level of entrepreneurs' mental model, has direct influence on entrepreneurs' daily performance, transmits to the other members of new enterprises in the form of rules and regulations, and becomes the behavioral model of the whole enterprise.

Conclusion of value realization: In the process of value realization, the knowledge on new value creation becomes more and more complete; the realization degree is higher and higher; and its reliance on entrepreneurs' mentality decreases gradually. After entrepreneurs' internal beliefs and schema are full externalized into clear business policies, systems and procedures, the knowledge on new value creation has been completely owned by new enterprises and all the members in the enterprises have become a part of the complete value production systems.

The process of new value creation works as injecting some liquid into a container; self-transcendence knowledge forms the container of entrepreneurs' mental model, which appears at the earliest time. Afterwards, deep belief is injected as the basic content of mental model and stays as the deepest position of mental model; the beliefs and schema at the shallow layer stay at the middle and upper layers. In real life, some entrepreneurs succeed, but more entrepreneurs fail. What characteristics of entrepreneurs' mental model can influence the realization of new value? Firstly, as self-transcendence knowledge, deep beliefs, shallow beliefs and schema are interacted, therefore, the more unanimous the relationship among the four is, the closer the relationship is, and the easier for entrepreneurs to succeed, the more smooth for the realization of new value.

Here, this paper puts forward Proposition 2: the process of new value realization includes three steps of value focus, policy establishment and mode anchor, which are specifically embodied in defining their goals and visions, establishing positioning of corresponding marketing, of production, research and development, and of management, and at last forming a set of stable and typical behavioral patterns in marketing, production, research and development and management.

Proposition 3: the more unanimous the relationship among entrepreneurs' entrepreneurial goals and visions, business policies and behavioral models, the closer the relationship is and the more smooth is the new value realization.

\section{Value Diffusion}

It has been mentioned in this paper that entrepreneurial opportunities come from entrepreneurs' view of looking at the world and they are not specific products or services, but a new kind of thinking modes. In this thinking mode, the original and perfect economic system becomes full of loopholes and new value appears, and its corresponding objects or carriers are not exclusive. In this process, entrepreneurs' mental models don't have overturning changes, but the previous mental models are enforced and improved.

\section{Conclusions}

This paper follows the schema of environmental construction theory, takes example by the theory of humanistic psychology to construct value creation mechanism of entrepreneurs, divides the mental process of entrepreneurs' new value creation into three stage of "opportunity emergence -- value realization -- value diffusion", and explains the entrepreneurship process systematically from the view of mental model development. Entrepreneurial opportunities are emerged self-transcendence knowledge in the consciousness driven by creative motivation, which are embodied in undifferentiated new value experience. In the value realization process, new value experience 
becomes gradually concrete; entrepreneurs' mental model grows clear and rich from original chaos; self-transcendence knowledge has definite deep beliefs and then corresponding shallow beliefs and schema form to guide entrepreneurs' behaviors directly, which becomes behavioral patterns of new enterprises to stabilize; then mental model of new value creation becomes complete gradually. The more accurately that entrepreneurs capture and grasp the core features of new value and build consistent mental model, and the more smoothly is the entrepreneurship process.

This paper adopts random effect model to make regression analysis on elements of affecting resources allocation efficiency of community sport. Resources allocation structure of mass sport, sport awareness of community residents, mass sport organization have obvious positive effect of increasing resources allocation efficiency of community sport, effect of regional economic development level on resources allocation efficiency of community sport is inconsistent with the original assumption, its main cause lies in that it has waste situation in the allocation process. Community resident awareness, education level has obvious effect on increasing index of technology advancement. Sport awareness of community residents has obvious effect on increasing technology efficiency of community sport resources allocation. Effect of Indexes such as consumption level of residents and regional economic development level, income level of residents, population scale and jurisdiction area, the number of community sport instructor etc on community sport allocation efficiency, technology efficiency and technology advancement has nor reached obvious level.

\section{Acknowledgment}

Fund Project: The research on enterprise vision of the National Natural Science Foundation of China: the dimension structure, the evolution mechanism and the way of realization (71172047)

\section{References}

[i] Shackle GLS.. Imagination and the Nature of Choice[M]. Edinburgh University Press: Edinburgh, U.K. ,1979.

[ii] Weick K. E. The Social Psychology of Organizing(2nd ed).[M]. Reading, MA: Addison Wesley, 1979.

[iii] Hill,R.C.,\& Levenhagen,M.. Metaphors and mental models: Sensemaking and sensegiving in innovative and entrepreneurial activities[J].Journal of Management, 1995;21(6):1057-1074.

[iv] Sarasvathy,S.D.. Causation and effectuation: Toward a theoretical shift from economic inevitability to entrepreneurial contingency[J]. Academy of Management Review,2001,.26(2):243-164.

[v] Baker,T.,\& Nelson,R.E.. Creating something from nothing: resource construction through entrepreneurial bricolage[J]. Administrative Science Quarterly, 2005, 50(3): 329-337.

[vi] Dimov,D.. From opportunity insight to opportunity intention: the importance of Person-situation learning match[J]. Entrepreneurship: Theory and Practice, 2007, 31(4): 561-583.

[vii] Felin,T. \& Zenger,T.R.. Entrepreneurs as Theorists: On the Origins of Collective Beliefs and Novel Strategies[J]. Strategic Entrepreneurship Journal,2009,3: 127 - 146.

[viii] Bird,B. Implementing Entrepreneurial Ideas: The Case for Intention[J].The Academy of Management Review,1988,13 (3) : 442-453.

[ ix ] Bird,B.J.. The Operation of Intentions in Time: The Emergence of the New Venture[J].Entrepreneurship Theory and Practice,1992,4: 11-20.

[x] Wood,M.S.,\& McKinley,W.. The Production of entrepreneurial opportunity: a constructivist perspective[J]. Strategic Entrepreneurship Journal,2010,4(1):66-84. 
[xi] Baron,R.A.. Opportunity recognition as pattern recognition: How entrepreneurs 'connect the dots' to identify new business opportunities[J].Academy of Management Perspectives, 2006,20(1):104-119.

[xii] Cardon,M.S.,Wincent,J.,Singh,J.,Drnovsek,M.. The nature and experience of entrepreneurial passion[J].Academy of Management Review,2009,34 (3) : 511-532.

[xiii] Kirzner, I.M.. Perception, Opportunity, and Profit. University of Chicago Press, Chicago, 1979. 